\title{
FURCATION FROM CLINICAL AND PERIODONTAL PERSPECTIVES
}

\author{
SUMAN MUKHERJEE ${ }^{1 *}$, SHARMISTHA DASGUPTA ${ }^{2}$
}

${ }^{1}$ Department of Periodontics and Oral Implantology, Periodontist and Oral Implants specialist at Arogya Bardini Polyclinic, Puruliya, West Bengal, India. Department of Periodontics and Oral Implantology, RHT Multispeciality Clinic, New Delhi, Indai. Email: smjee234@gmail.com

Received: 16 January 2021, Revised and Accepted: 04 March 2021

ABSTRACT

The article gives a recent update of change in clinical and periodontal perspectives in furcation in recent times.

Keywords: Furcation, Hemisection, Review, Periodontal, Radiograph, GTR, Grafts, Implant, Stem cells, Treatment.

(C) 2021 The Authors. Published by Innovare Academic Sciences Pvt Ltd. This is an open access article under the CC BY license (http://creativecommons.org/ licenses/by/4.0/) DOI: http://dx.doi.org/10.22159/ajpcr.2021v14i4.40809. Journal homepage: https://innovareacademics.in/journals/index.php/ajpcr

\section{INTRODUCTION}

Periodontitis is one of the most common diseases of mankind. Progression of periodontitis destroys the teeth supporting structures, without therapy at the end leading to loss of teeth. The most common outcome of periodontal disease is gingival recession, mobility, and tooth loss. Furcation is an outcome of moderate to advanced periodontitis, where the loss of attachment progress beyond the cementoenamel junction involving the root.

In this article, we would discuss only the present-day progress, clinical relevance, and an immediate perspective of furcation.

Furcation is defined in several ways by different authors. In brief, we can define it as a condition in multi-rooted teeth, where the root bifurcation region is detached from the attached gingiva.

The major causes of furcation are the same as those of periodontitis. Dental plaque is the primary etiology factor $[1,2]$. Plaque deposition leads to chronic inflammation, sequela of which causes loss of attachment (key sign of periodontitis) leading to furcation involvement. Sometimes other diseases and conditions like, endo-perio lesions, bacterial and viral infections, and compromised conditions, for example, uncontrolled diabetes, obesity, and smoking can escalate the severity and rate of progression of furcation involvement. Besides these factors, there are several predisposing and contributing factors that are mentioned in the literature.

Innumerable classification for horizontal and vertical involvement of furcation is described in the literature. Still, there is no universally accepted classification for furcation involvement. The most used classifications are Glickman's horizontal classification [3], Goldman and Cohen's [4]. For vertical either of the Tarnow and Fletcher [5] or
Eskow and Kapin's [6] classification is commonly used. In 2018, Pilloni and Rojas [7] came up with a new classification, where they classified the furcation involvement bases on exposed and non-exposed surfaces. However, even this new proposed classification has a fixed disadvantage. Hence, its still a vague and unquestionably unsolved subject.

Probes are still the hallmark of clinical diagnosis. Furcation involvement cannot be precisely diagnosed by visual intraoral examination. As such we either use straight probes or the Quentin probes for clinical diagnosis of furcation involvement (Fig. 1).

For measuring the furcation involvement and record its changes we use the relative attachment level index, where we measure the distance from a clinical reference point until the tip of the probe. Few studies compared the pre-surgical and post-surgical measurements of FI using the Nabers probe, throttle position sensor (TPS), and PCPUNC15 probes. The studies reported no statistically significant difference between the pre-and post-surgical readings [8-10]. However, one study reported that the later probes (TPS and PCPUNC15) underestimated the CAL - Horizontal for distolingual furcation and furcation degrees $(\mathrm{p}<0.1)[11]$.

The radiographic gold standard for diagnosing FI is CBCT. A diverse number of studies compared CBCT with presurgical and intra surgical (IS) measurements and found CBCT having agreeable or better accuracy compared to probing and intra-surgical measurements [12-15].

RadioVisioGraphy (RVG) is a 2D digital imaging aid that projects the image directly in the monitor. Studies comparing RVG and IOPA found no statistical difference, as both underestimated the FI measurements when compared to IS [16].
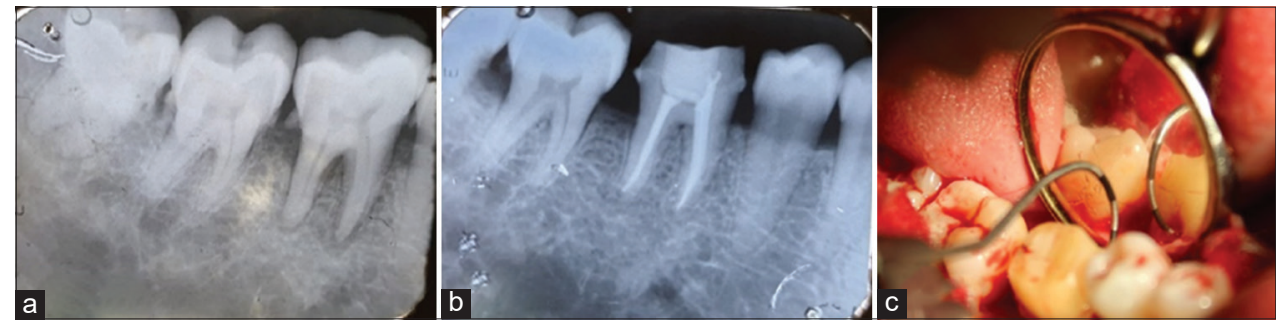

Figure 1: (a) Furcation involvement in 46, endo-perio lesion (b) Even after successful root canal treatment (RCT), the furcation defect persisted. 3 month post RCT IOPA (c) Flap reflection and direct measurement of furcation horizontal attachment levels defect using Nabers probe 

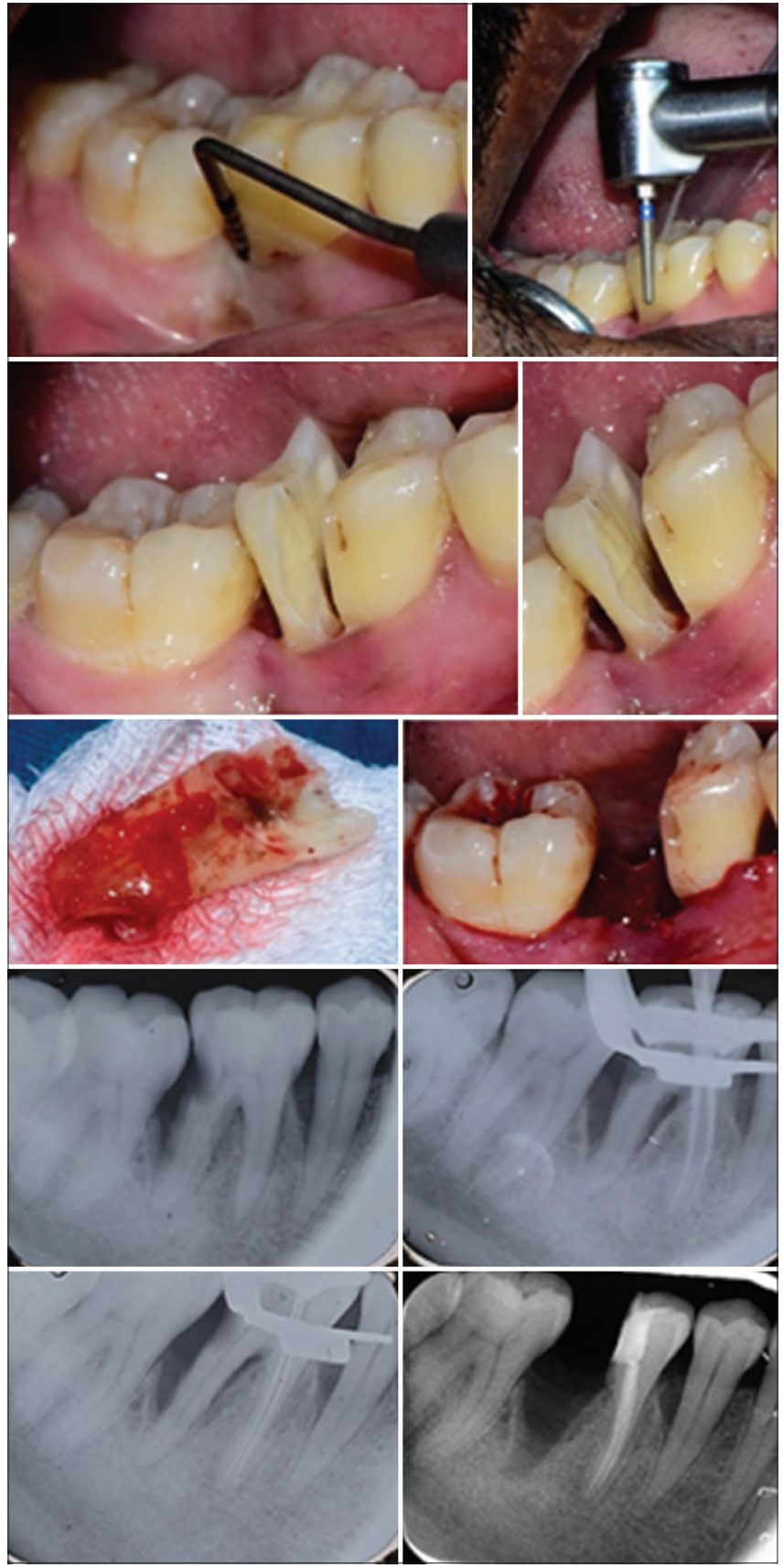

Figure 2: Hemisection of furcation involved teeth, with IOPA

\section{Recent frontiers}

Ultrasound: Is a non-invasive aid that is under validation for use for measurement and assessment of alveolar bone levels and furcation involvement. There is no concrete evidence on the accuracy and usefulness of this, but a single article reported the UltraSound has $76 \%$ accuracy compared to surgical measurements (clinical measurements showed 70\%) [17].

Natural frequency is the measurement of dynamic response to vibrating objects which is correlated to the material properties and boundaries of the structure. In this method, electronic transducer and materials are used to assess bone loss and change bone levels using a 3D infinite element model [18]. At present, not much research is available to validate its use in periodontal FI or bone levels assessments.

Optical coherence tomography is another recent speculative aid that might be used in the future for the assessment of periodontal

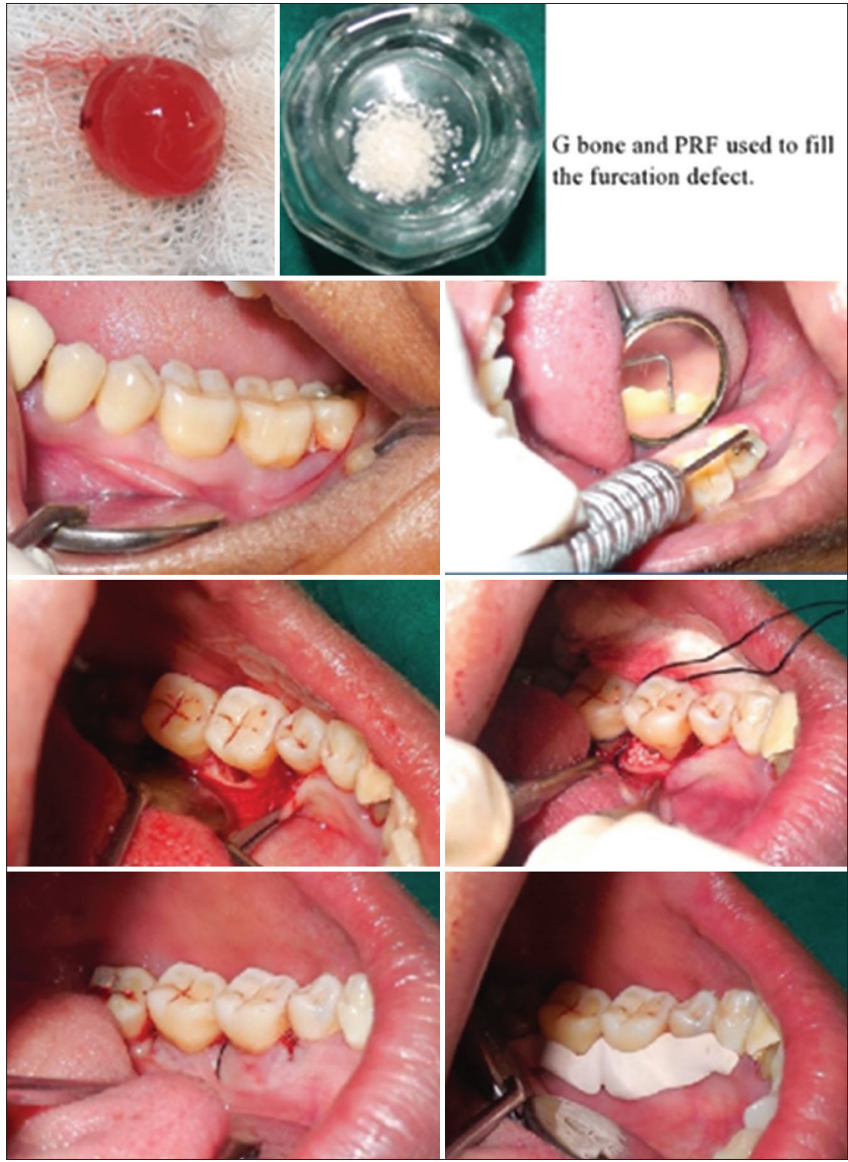

Figure 3: Regenerative procedures like Bone grafts along with PRF can be used to fill the furcation defects with an excellent outcome. In this case, we used a Bone graft (G bone) along with PRF.

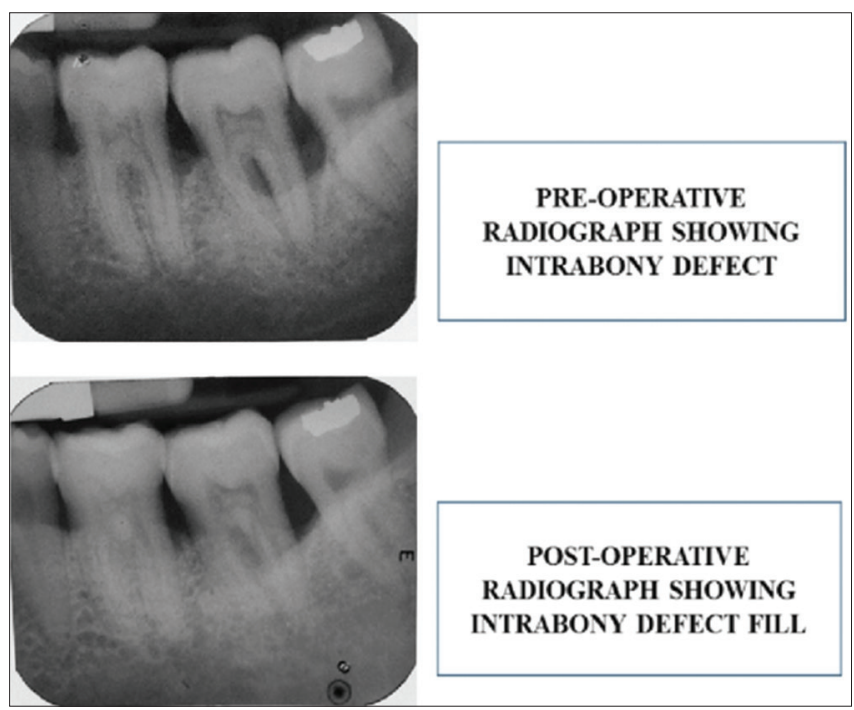

1Figure 4:

defects. It is non-invasive as it uses natural white light to assess bone levels. Two articles reported its usefulness in periodontics, to precisely measure the volume and distance of hard and soft tissues. This diagnostic aid also gives better lateral and axial optical resolution and good microstructural details $[19,20]$. With this aid visual recordings of periodontal tissue contour, sulcular depth, and connective tissue attachment are possible. However, we need more research to conclude. 
Once we've done the diagnosed furcation during a visit, therapy is requisite for containing its further progression and restore periodontium to health.

\section{Treatment plan}

While planning the treatment, two main requisites are: (i) remove the key etiological and contributing factors, for example., plaque, calculus, etc., (ii) symptomatic treatment and stabilizing the periodontium by splinting of loose teeth, treatment of root sensitivity, caries, or associated endo-period lesions. Each article and authors suggest their separate treatment plan, but from a clinical and periodontal perspective we've to know, no treatment plan will suit all cases. Each case will present its unique challenges, and we've to plan treatment for each patient based on their needs, demands, cooperation, and financial challenges. At present, the stress and habits of patients present many challenges to maintain the periodontal basic satisfactory hygiene, as such most regenerative and restorative treatments would fail. Without proper care, even fixed prosthetic treatment such as implants and fixed partial denture wouldn't last long.

The most ordinary way furcation was treated in past was by restoring the bifurcation convergence with dental cement-like calcium phosphate and glass ionomer cement. It provided temporary relief from root sensitivity, food impaction and provided a long-term solution at a reasonable price for geriatric patients.

Scaling and root planning are very crucial for a successful transition from health to disease, and long-term stability and results.

Over the years till the 2000s, resective surgeries were tried for the treatment of furcation. Hemisection (Fig. 2), root resection, and osseous contouring such as tunnel technique have been tried with successful results over long years of follow-ups. In the post-2000s, regenerative techniques came into the picture, guided tissue regeneration and bone grafts (Figs. 3 and 4) along with access flap have given convincing results.

The major roadblock for choosing treatment options is which materials to choose, when, and the host tissue response to treatment.

Alas, when every other treatment fails, or progress seems questionable extraction seems to be the best option.

In the present scenario, patients usually prefer extraction and prosthetic replacement compared to the long-term treatment plans to keep the teeth because of constraints in time and disparity of results.

As such, although furcation has been a long dilemma in periodontics, in the present era the scope and prospects seem limited. The theme nowadays is to remove whatever cannot be changed. Root hypersensitivity and pain (due to root caries) being the most common causes for patients to visit the dental clinic.

The recent treatment development depends on stem cells and their application. Lasers have been used to regenerate teeth from stem cells in vivo [21-25]. The future of furcation belongs to stem cells and implants.

\section{CONCLUTION}

The main changes in the past 5-10 years have been seen in the development of new diagnostic aids, which are non-invasive yet expensive. The therapy is swiftly shifting through the decades from resective (pre-2000s) to regenerative (the 2000s-2020) to removal. (2020 onwards). as such, we have to decide on a treatment plan for each patient based on their needs, demand, cooperation, and financial status.

\section{AUTHORS CONTRIBUTION}

Dr. Suman Mukherjee has written the manuscript; Dr. Sharmistha Dasgupta provided the first and third images, and collected the data, edited the whole manuscript.

\section{CONFLICTS OF INTERESTS}

Nil.

\section{AUTHORS FUNDING}

Nil.

\section{REFERENCES}

1. Löe H, Anerud A, Boysen H, Morrison E. Natural history of periodontal disease in man. Rapid, moderate and no loss of attachment in Sri Lankan laborers 14 to 46 years of age. J Clin Periodontol 1986;13:431-45.

2. Waerhaug J. The furcation problem. Etiology, pathogenesis, diagnosis, therapy and prognosis. J Clin Periodontol 1980;7:73-95

3. Glickman I. Bifurcation involvement in periodontal disease. J Am Dent Assoc 1950:40:528-38

4. Goldman HM, Cohen DW. Periodontal Therapy. $6^{\text {th }}$ ed. St. Louis, IL: C.V. Mosby; 1988. p. 921.

5. Tarnow D, Fletcher P. Classification of the vertical component of furcation involvement. J Periodontol 1984;55:283-4.

6. Eskow RN, Kapin SH. Furcation invasions: Correlating a classification system with therapeutic considerations. Part I. Examination, diagnosis, and classification. Compend Contin Educ Dent 1984;5:477-87.

7. Pilloni A, Rojas MA. Furcation involvement classification: A comprehensive review and a new system proposal. Dent J (Basel) 2018;6:34

8. Eickholz P. Reproducibility and validity of furcation measurements as related to class of furcation invasion. J Periodontol 1995;66:984-9.

9. Eickholz P, Staehle HJ. The reliability of furcation measurements. J Clin Periodontol 1994;21:611-4.

10. Eickholz P, Kim TS. Reproducibility and validity of the assessment of clinical furcation parameters as related to different probes. J Periodontol 1998;69:328-36.

11. Zhang W, Foss K, Wang BY. A retrospective study on molar furcation assessment via clinical detection, intraoral radiography and cone beam computed tomography. BMC Oral Health 2018;18:75.

12. Padmanabhan S, Dommy A, Guru SR, Joseph A. Comparative evaluation of cone-beam computed tomography versus direct surgical measurements in the diagnosis of mandibular molar furcation involvement. Contemp Clin Dent 2017;8:439-45.

13. Komšić S, Plančak D, Kašaj A, Puhar I. A comparison of clinical and radiological parameters in the evaluation of molar furcation involvement in periodontitis. Acta Stomatol Croat 2019;53:326-36.

14. Aghanashini S, Jayachandran C, Mundinamane DB, Nadiger S, Bhat D, Andavarapu $\mathrm{S}$, et al. Comparison of the furcation involvement by clinical probing and cone beam computed tomography with true level of involvement during flap surgery. World J Dent 2017;8:267-72.

15. Parvez MF, Manjunath N, Kini R. Comparative assesment of accuracy of IOPA and CBCT for maxillary molar furcation involvement: A clinical and radiological study. Int J Res Med Sci 2018:6:1765-9.

16. Ashwinirani SR, Suragimath G, Jaishankar HP, Kulkarni P, Bijjaragi SC, Sangle VA. Comparison of diagnostic accuracy of conventional intraoral periapical and direct digital radiographs in detecting interdental bone loss. J Clin Diagn Res 2015;9:ZC35-8.

17. Chandrashekhar KT, Vandana KL, Mehta DS. Comparative Evaluation of Ultrasonography, Clinical and Surgical Measurements of Furcation Involvement: A Clinical Study. Available from: http://www. ypographicsplus.com/journals/index.php/JIDA/article/view/269. [Last accessed on 2014 Sep 11].

18. Wang CH, Ou KL, Chang WJ, Teng NC, Yu JJ, Huang HM. Detection of the furcation involvement of a multi-rooted molar using natural frequency analysis: A numerical approach. Proc Inst Mech Eng $\mathrm{H}$ 2009:223:375-82.

19. Colston BW, Everett MJ, Sathyam US, DaSilva LB, Otis LL. Imaging of the oral cavity using optical coherence tomography. Monogr Oral Sci 2000;17:32-55.

20. Otis LL, Everett MJ, Sathyam US, and Colston BW. Optical coherence tomography: A new imaging technology for dentistry. J Am Dent Assoc 
2000;131:511-4.

21. Kim HB, Baik KY, Seonwoo H, Jang KJ, Lee MC, Choung PH, et al. Effects of pulsing of light on the dentinogenesis of dental pulp stem cells in vitro. Sci Rep 2018;8:2057.

22. Bakhtiar H, Mazidi SA, Mohammadi Asl S, Ellini MR, Moshiri A, Nekoofar $\mathrm{MH}$, et al. The role of stem cell therapy in regeneration of dentine-pulp complex: A systematic review. Prog Biomater 2018; 7:249-68.

23. De Freitas LF, Hamblin MR. Proposed mechanisms of photobiomodulation or low-level light therapy. IEEE J Sel Top Quantum Electron 2016;22:348-64.

24. Xuan K, Li B, Guo H, Sun W, Kou X, He X, et al. Deciduous autologous tooth stem cells regenerate dental pulp after implantation into injured teeth. Sci Transl Med 2018;10:eaaf3227.

25. Arany PR, Cho A, Hunt TD, Sidhu G, Shin K, Hahm E, et al. Photoactivation of endogenous latent transforming growth factor- $\beta 1$ directs dental stem cell differentiation for regeneration. Sci Transl Med 2014;6:238ra69. 